\title{
Association of transforming growth factor-beta 1 gene polymorphism with genetic susceptibility to ossification of the posterior longitudinal ligament in Korean patients
}

\author{
I.B. Han ${ }^{1 *}$, A.E. Ropper 2,3*, Y.J. Jeon ${ }^{4}$, H.S. Park ${ }^{5}$, D.A. Shin ${ }^{5}$, \\ Y.D. Teng ${ }^{2,3}$, S.-U. Kuh ${ }^{5}$ and N.-K. Kim ${ }^{4}$ \\ ${ }^{1}$ Department of Neurosurgery, CHA Bundang Medical Center, \\ CHA University, Seongnam, South Korea \\ ${ }^{2}$ Department of Neurosurgery, Brigham and Women's Hospital, \\ Department of Physical Medicine and Rehabilitation, \\ Spaulding Rehabilitation Hospital, Harvard Medical School, Boston, MA, USA \\ ${ }^{3}$ Division of SCI Research, Veterans Affairs Boston Healthcare System, \\ Boston, MA, USA \\ ${ }^{4}$ Institute of Clinical Research, CHA Bundang Medical Center, \\ CHA University, Seongnam, South Korea \\ ${ }^{5}$ Department of Neurosurgery, Spine and Spinal Cord Institute, \\ College of Medicine, Yonsei University, Seoul, South Korea \\ *These authors contributed equally to this study. \\ Corresponding authors: N.-K. Kim / S.-U. Kuh \\ E-mail: neurosci70@yahoo.com/nshanib@naver.com
}

Genet. Mol. Res. 12 (4): 4807-4816 (2013)

Received July 27, 2012

Accepted November 22, 2012

Published February 28, 2013

DOI http://dx.doi.org/10.4238/2013.February.28.26

\begin{abstract}
Ossification of the posterior longitudinal ligaments (OPLL) has been considered to be associated with abnormalities of bone metabolism, and transforming growth factor- $\beta 1$ (TGF- $\beta 1$ ) has been demonstrated to affect the bone remodeling process. We investigated two SNPs of the TGF- $\beta 1$ promoter $(-509 \mathrm{C}>\mathrm{T}$; rs 1800469$)$ and exon 1 (869T>C; rs1982073) in 298 Koreans (98 patients with OPLL and 200 control subjects). The promoter SNP $-509 \mathrm{C}>\mathrm{T}$ was determined by
\end{abstract}


PCR and RFLP, and the TaqMan probe assay was used to determine 869T $>$ C polymorphism genotypes. The subjects were divided into OPLL continuous group (continuous type plus mixed type) and OPLL segmental group (segmental and localized type). We also separately analyzed this association according to gender difference. There was no significant difference in genotype distributions of $-509 \mathrm{C}>\mathrm{T}$ and $869 \mathrm{~T}>\mathrm{C}$ polymorphisms of the TGF- $\beta 1$ gene between OPLL patients and controls. A combined analysis of TGF- $\beta 1-509 \mathrm{C}>\mathrm{T}$ and $869 \mathrm{~T}>\mathrm{C}$ polymorphisms showed no significant association with OPLL, and a subgroup analysis did not show any significant correlation between the SNP -509 C $>$ T or SNP 869T $>$ C and OPLL subgroups. Stratification by gender demonstrated no significant effect. We conclude that promoter region $(-509 \mathrm{C}>\mathrm{T})$ and exon $1 \quad(869 \mathrm{~T}>\mathrm{C})$ polymorphisms are not associated with OPLL in the Korean population.

Key words: Ossification; Posterior longitudinal ligament; Polymorphism; Transforming growth factor- $\beta 1$

\section{INTRODUCTION}

Ossification of the posterior longitudinal ligament (OPLL) is characterized by ectopic ossification in the spinal ligaments. Abnormalities of bone metabolism play an important role in the occurrence of OPLL (Matsui et al., 1996). Both environmental and genetic factors are believed to contribute to individual susceptibility to OPLL (Saetia et al., 2011). Many research groups have investigated the associations between specific polymorphisms of bone metabolism-related genes and genetic susceptibility to OPLL (Kamiya et al., 2001; Kawaguchi et al., 2003; Tsukahara et al., 2005; Kobashi et al., 2008; Wang et al., 2008; Liu et al., 2010). To date, however, highly relevant genes responsible for the occurrence of OPLL have not been precisely defined.

Transforming growth factor- $\beta 1$ (TGF- $\beta 1$ ) is one of the suggested candidate genes that contribute to genetic risk factors for OPLL occurrence for the following reasons. First, TGF- $\beta 1$ is an important regulator of bone metabolism, showing strong evidence of profound effects on the bone remodeling processes of bone resorption and formation (Kamiya et al., 2001; Kawaguchi et al., 2003, Janssens et al., 2005). Second, TGF- $\beta 1$ is present in the ossified matrix and chondrocytes in cartilaginous areas adjacent to OPLL pathology (Kawaguchi et al., 2003; Inamasu et al., 2006). Third, TGF- $\beta 1$ reportedly modulates bone development and fracture healing (Aufdemorte et al., 1992; Kawaguchi et al., 2003). Local administration of TGF- $\beta 1$ has been reported to induce fracture healing or bone formation in animals (Schmidmaier et al., 2002). Finally, TGF- $\beta 1$ knockout mice display reduced bone mass and elasticity (Geiser et al., 1998).

The TGF- $\beta$ family consists of three isoforms - TGF- $\beta 1$, TGF- $\beta 2$, and TGF- $\beta 3$ - with TGF- $\beta 1$ being the most abundant in the bone matrix compared with levels in other tissues (Patil et al., 2011). Single nucleotide polymorphisms (SNPs) in the TGF- $\beta 1$ gene have been detected in the coding region of the TGF- $\beta 1$ gene and its promoter region. So far, only three studies have been conducted to determine potential association between OPLL occurrence and SNP 869T $>$ C at exon 1 nucleotide position 29 in the coding region; the results, however, have been inconsistent and inconclusive (Kamiya et al., 2001; Kawaguchi et al., 2003; Horikoshi 
et al., 2006). Polymorphism in the promoter region of TGF- $\beta 1$ gene can also affect TGF- $\beta 1$ expression. The promoter SNP $-509 \mathrm{C}>\mathrm{T}$ reportedly contributes to osteoporosis by influencing bone mass (Yamada et al., 2001; Langdahl et al., 2003). However, no published studies have explored possible associations between polymorphisms in the TGF- $\beta 1$ gene promoter region and susceptibility to OPLL. We therefore aimed to investigate whether promoter SNP -509C $>\mathrm{T}$ or exon 1 polymorphism at +869 (SNP $869 \mathrm{~T}>\mathrm{C})$ are associated with genetic susceptibility to OPLL in a Korean population.

\section{MATERIAL AND METHODS}

\section{Study population}

The case-control population contained 298 adult unrelated Koreans selected from the same population living in Korea between 2008 and 2010. A total of 98 cervical OPLL patients (66 men, 32 women; mean age \pm standard deviation, $52.9 \pm 8.7$ years) were recruited from Gangnam Severance Hospital, Yonsei Medical University (Seoul, South Korea). The presence of OPLL was determined from radiographic criteria based on computed tomography of the cervical spine. OPLL cases were classified into four subtypes: 1) continuous, involving a long lesion extending over several vertebral bodies; 2) segmental, involving one or several separate lesions behind the vertebral bodies; 3 ) mixed, which is a combination of the continuous and segmental types; and 4) localized, involving a lesion mainly located posterior to a disc space. Compared with segmental and localized subtypes, the mixed and continuous subtypes of OPLL reportedly have the greatest risk of progression of the ossification area. Therefore, we categorized the cases into two groups, an OPLL segmental (segmental type plus localized type OPLL) and an OPLL continuous (continuous type plus mixed type OPLL), based on previous reports (Kawaguchi et al., 2001; Hori et al., 2006; Kudo et al., 2011).

Bone mineral density (BMD) was measured using dual-energy X-ray absorptiometry of the lumbar spine and proximal femur. Standard laboratory examinations and thyroid hormone level measurements were performed routinely. Patients with disorders such as hyperthyroidism, primary hyperparathyroidism, or pituitary diseases and those receiving treatments including oral contraceptives, hormones replacement therapy, glucocorticoids, calcium, or vitamin $\mathrm{D}$ that have potential to interfere with bone metabolism were excluded from the study. We also excluded the patients who had ankylosing spondylitis, osteoporosis, and diffuse idiopathic skeletal hyperostosis.

The control group comprised 200 healthy volunteers who visited the general health checkup division at Gangnam Severance Hospital, Yonsei Medical University. The mean age of the patients in the control group (115 men and 85 women) was 53.5 years (standard deviation, 9.5 years). Cervical spine computed tomography showed no evidence of OPLL in controls. The study was approved by the institutional review board of Gangnam Severance Hospital, and written informed consent was obtained from all participants.

\section{Genotype analysis using polymerase chain reaction restriction fragment length polymorphism (PCR-RFLP) assay}

Genotype analysis of the $-509 \mathrm{C}>\mathrm{T}$ polymorphism of the TGF- $\beta 1$ gene was performed via PCR-RFLP assay. Genomic DNA was extracted from peripheral blood leukocytes by us- 
ing a G-DEX blood extraction kit (iNtRON Biotechnology, Inc., Seongnam, South Korea). The PCR primers were 5'-CAG TAA AGG AGA GCA ATT CTT AC-3' (forward) and 5'-GGT CAC CAG AGA AAG AGG AC-3' (reverse). Genomic DNA was amplified with PCR buffer containing $50 \mathrm{~mL} \mathrm{KCl}, 10 \mathrm{mM}$ Tris- $\mathrm{HCl}$ buffer, $\mathrm{pH} 8.3,1.5 \mathrm{mM} \mathrm{MgCl}, 0.2 \mathrm{mM}$ of each deoxynucleotide triphosphate, $10 \mathrm{pM}$ each primer, and 1 unit Taq polymerase (Takara, Madison, WI, USA). The PCR cycling conditions consisted of an initial denaturation step at $94^{\circ} \mathrm{C}$ for 5 min followed by 35 cycles of $30 \mathrm{~s}$ at $94^{\circ} \mathrm{C}, 35 \mathrm{~s}$ at $58^{\circ} \mathrm{C}, 30 \mathrm{~s}$ at $72^{\circ} \mathrm{C}$, and a final extension at $72^{\circ} \mathrm{C}$ for 5 min. The PCR products were digested with DdeI (New England Biolabs, Ipswich, MA, USA) and analyzed with electrophoresis on $3 \%$ agarose gel.

\section{Genotype analysis with TaqMan assays}

TaqMan assay probes for SNP 869T $>$ C were designed by Applied Biosystems (Foster City, CA, USA). The forward primer was 5'-CCC ACC ACAC CAG CCC TGT TC-3', and the reverse primer was 5'-TTC CGC TTC ACC AGC TCC ATG T-3'. The TaqMan probe for the detection of the T allele was FAM-TAG CAG CAG CAG CAG CAG CCG C-BHQ1, and the probe for the detection of the $\mathrm{C}$ allele was HEX-TAG CAG CAG CGG CAG CAG CCG$\mathrm{BHQ} 1$. The PCR program included an initial denaturation step at $95^{\circ} \mathrm{C}$ for 5 min followed by 45 cycles of denaturation at $95^{\circ} \mathrm{C}$ for $15 \mathrm{~s}$ and annealing/extension at $65^{\circ} \mathrm{C}$ for $20 \mathrm{~s}$. PCR, endpoint fluorescence reading, and analysis of the data were performed with a 7500 Real Time PCR System (Applied Biosystems).

\section{Statistical analysis}

Genotype frequencies were compared between OPLL patients and controls using the chi-square test and the Fisher exact test when appropriate, and odds ratios and $95 \%$ confidence intervals were calculated to estimate the relative risk of OPLL conferred by each polymorphism. Association of SNPs with OPLL was analyzed with multivariate logistic regression adjusted for possible confounders, including age, gender, diabetes mellitus (DM), and BMD. Demographic data between groups were compared using the chi-square test for categorical variables such as gender and the prevalence of DM and using the Mann-Whitney test for quantitative variables such as age and BMD values. Statistical analyses were performed using SPSS for Windows 11.0 (SPSS Inc., Chicago, IL, USA) and the StatsDirect Statistical Software (version 2.4.4, StatsDirect Ltd., Altrincham, UK). The level of statistical significance was set at $\mathrm{P}<0.05$.

\section{RESULTS}

The demographics of the patients and controls enrolled in this study are summarized in Table 1. No significant differences were found between patients and controls for mean age or gender distribution (see Table 1). No significant differences between the two groups were found with respect to BMD and the prevalence of DM (data not shown). Of the 98 OPLL patients, 64 belonged to the OPLL continuous group (continuous type, $\mathrm{N}=30$; plus mixed type, $\mathrm{N}=34$ ), and 34 belonged to the OPLL segmental group (segmental type, $\mathrm{N}=17$; plus localized type, $\mathrm{N}=17$; see Table 1 ). 
Table 1. Characteristics of patients with ossification of posterior longitudinal ligaments (OPLL) and controls.

\begin{tabular}{lccc}
\hline Characteristics & OPLL patients & Controls & $\mathrm{P}^{\mathrm{a}}$ \\
\hline Number (N) & 98 & 200 & \\
Age [years, mean $\pm \mathrm{SD}]$ & $52.93 \pm 8.66$ & $53.47 \pm 9.47$ & 0.634 \\
Male gender [N, \%] & $66(67.3 \%)$ & $115(57.5 \%)$ & 0.102 \\
OPLL group & $64(65.3 \%)$ & & \\
Continuous group (continuous + mixed type) & $34(34.7 \%)$ & & \\
Segmental group (segmental + localized) & & \\
\hline
\end{tabular}

Values are reported as means \pm SD. ${ }^{\text {aC Calculated by the Mann-Whitney test for continuous data and the chi-square }}$ test for categorical data.

The genotype frequencies of the TGF- $\beta 1-509 \mathrm{C}>\mathrm{T}$ and $869 \mathrm{~T}>\mathrm{C}$ polymorphisms among patients and controls are shown in Table 2. The genotype distributions of both polymorphisms among patients and controls were in Hardy-Weinberg equilibrium. The frequencies of the CC, CT, and TT genotypes of SNP $-509 \mathrm{C}>\mathrm{T}$ were $27.0,48.5$, and $24.5 \%$ in controls and $25.5,51.0$, and $23.5 \%$ in patients, respectively. The frequencies of the TT, TC, and CC genotypes of SNP $869 \mathrm{~T}>\mathrm{C}$ were $26.5,49.0$, and $24.5 \%$ in controls and $25.5,49.0$, and $25.5 \%$ in patients, respectively. The frequencies of the $-509 \mathrm{~T}$ and $869 \mathrm{C}$ alleles were 0.523 and 0.524 in controls and 0.490 and 0.500 in patients, respectively. No significant differences were found in the genotype frequencies of the TGF- $\beta 1-509 \mathrm{C}>\mathrm{T}$ and $869 \mathrm{~T}>\mathrm{C}$ polymorphisms between OPLL patients and controls (see Table 2). The combined genotype frequencies of TGF- $\beta 1$ $-509 \mathrm{C}>\mathrm{T}$ and $869 \mathrm{~T}>\mathrm{C}$ polymorphisms of patients and controls are also presented in Table 2. OPLL patients exhibited no significant differences in combined genotype frequencies relative to the controls. When OPLL patients were divided into the continuous and segmental groups, the association of TGF- $\beta 1-509 \mathrm{C}>\mathrm{T}$ and $869 \mathrm{~T}>\mathrm{C}$ polymorphisms with OPLL was not determined (Table 3). Genotype frequencies of the two polymorphisms were also estimated according to gender, but stratification for gender yielded no significant results (Table 4).

\begin{tabular}{|c|c|c|c|c|}
\hline & Controls $(\mathrm{N}=200)$ & OPLL patients $(\mathrm{N}=98)$ & AOR $(95 \% \mathrm{CI})$ & $\mathrm{P}$ \\
\hline \multicolumn{5}{|l|}{ TGF- $\beta 1-509$} \\
\hline $\mathrm{CC}$ & $54(27.0)$ & $25(25.5)$ & 1.000 & \\
\hline CT & $97(48.5)$ & $50(51.0)$ & $1.122(0.623-2.023)$ & 0.702 \\
\hline TT & $49(24.5)$ & $23(23.5)$ & $1.082(0.537-2.181)$ & 0.826 \\
\hline Dominant $(\mathrm{CC} v s \mathrm{CT}+\mathrm{TT})$ & & & $1.115(0.640-1.943)$ & 0.701 \\
\hline Recessive (CC+CT vs TT) & & & $1.026(0.575-1.829)$ & 0.931 \\
\hline \multicolumn{5}{|l|}{ TGF- $\beta 1869$} \\
\hline TT & $53(26.5)$ & $25(25.5)$ & 1.000 & \\
\hline $\mathrm{TC}$ & $98(49.0)$ & $48(49.0)$ & $1.020(0.564-1.845)$ & 0.948 \\
\hline $\mathrm{CC}$ & $49(24.5)$ & $25(25.5)$ & $1.173(0.588-2.341)$ & 0.650 \\
\hline Dominant $(\mathrm{TT} v s \mathrm{TC}+\mathrm{CC})$ & & & $1.066(0.612-1.859)$ & 0.821 \\
\hline Recessive (TT+TC vs CC) & & & $1.137(0.646-2.003)$ & 0.656 \\
\hline \multicolumn{5}{|l|}{ TGF- $\beta 1-509 / 869$} \\
\hline $\mathrm{CC} / \mathrm{TT}$ & $51(25.5)$ & $25(25.5)$ & 1.000 & \\
\hline $\mathrm{CC} / \mathrm{CT}$ & $3(1.0)$ & $0(0.0)$ & NA & \\
\hline $\mathrm{CC} / \mathrm{CC}$ & $0(0.0)$ & $0(0.0)$ & NA & \\
\hline $\mathrm{CT} / \mathrm{TT}$ & $2(1.0)$ & $0(0.0)$ & NA & \\
\hline $\mathrm{CT} / \mathrm{CT}$ & $95(47.5)$ & $47(48.0)$ & $0.999(0.549-1.818)$ & 0.998 \\
\hline $\mathrm{CT} / \mathrm{CC}$ & $0(0.0)$ & $3(3.1)$ & NA & \\
\hline $\mathrm{TT} / \mathrm{TT}$ & $0(0.0)$ & $0(0.0)$ & NA & \\
\hline $\mathrm{TT} / \mathrm{CT}$ & $0(0.0)$ & $1(1.0)$ & NA & \\
\hline $\mathrm{TT} / \mathrm{CC}$ & $49(24.5)$ & $22(22.4)$ & $0.986(0.486-2.000)$ & 0.968 \\
\hline
\end{tabular}

$\mathrm{AOR}=$ adjusted odds ratio; $95 \% \mathrm{CI}=95 \%$ confidence interval; $\mathrm{NA}=$ not available; $\mathrm{TGF}-\beta 1=$ transforming growth factor- $\beta 1$. $P$ values were adjusted for age and gender. 
I.B. Han et al.

4812

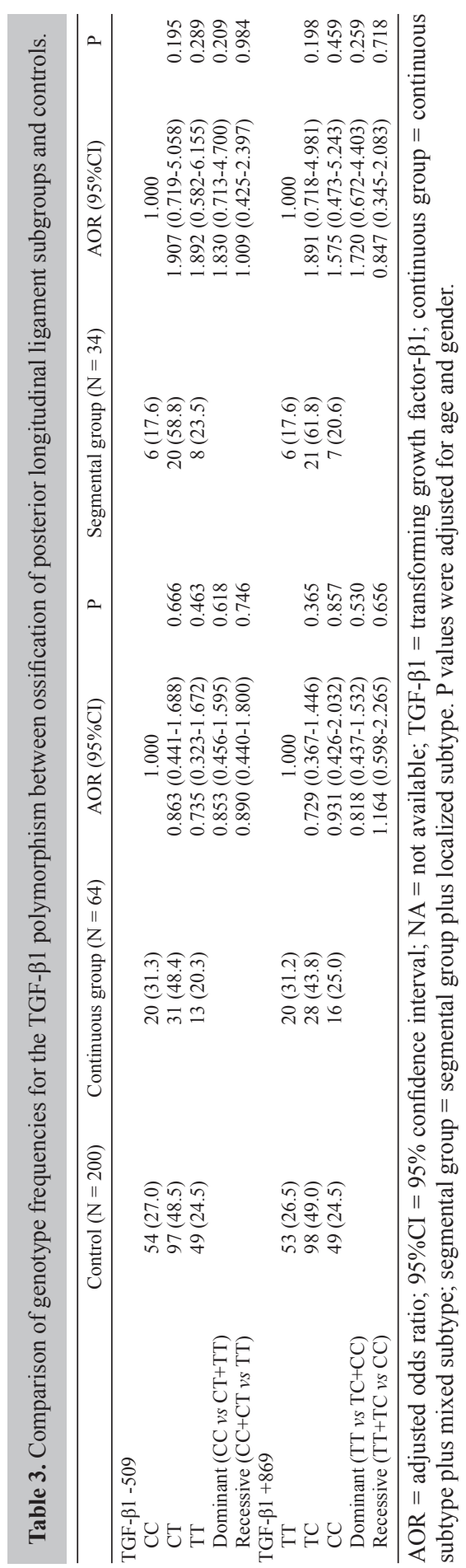

Genetics and Molecular Research 12 (4): 4807-4816 (2013)

CFUNPEC-RP www.funpecrp.com.br 


\begin{tabular}{|c|c|c|c|c|}
\hline & Controls & OPLL patients & $\operatorname{AOR}(95 \% \mathrm{CI})$ & $\mathrm{P}$ \\
\hline Male & $\mathrm{N}=115$ & $\mathrm{~N}=66$ & & \\
\hline \multicolumn{5}{|l|}{ TGF- $\beta 1-509$} \\
\hline $\mathrm{CC}$ & $33(28.7)$ & $19(28.8)$ & 1.000 & \\
\hline $\mathrm{CT}$ & $59(51.3)$ & $36(54.5)$ & $1.051(0.521-2.123)$ & 0.889 \\
\hline $\mathrm{TT}$ & $23(20.0)$ & $11(16.7)$ & $0.822(0.329-2.057)$ & 0.676 \\
\hline Dominant $(\mathrm{CC} v s \mathrm{CT}+\mathrm{TT})$ & & & $0.996(0.509-1.948)$ & 0.991 \\
\hline Recessive $(\mathrm{CC}+\mathrm{CT}$ vs TT) & & & $0.824(0.372-1.827)$ & 0.634 \\
\hline \multicolumn{5}{|l|}{ TGF- $\beta 1869$} \\
\hline TT & $31(27.0)$ & $19(28.8)$ & 1.000 & \\
\hline $\mathrm{TC}$ & $61(53.0)$ & $33(50.0)$ & $0.847(0.413-1.736)$ & 0.649 \\
\hline $\mathrm{CC}$ & $23(20.0)$ & $14(21.2)$ & $0.994(0.414-2.390)$ & 0.990 \\
\hline Dominant (TT vs $\mathrm{TC}+\mathrm{CC})$ & & & $0.892(0.453-1.756)$ & 0.741 \\
\hline Recessive (TT+TC vs CC) & & & $1.118(0.527-2.370)$ & 0.772 \\
\hline Female & $\mathrm{N}=85$ & $\mathrm{~N}=32$ & & \\
\hline TGF- $\beta 1-509$ & & & & \\
\hline $\mathrm{CC}$ & $21(24.7)$ & $6(18.8)$ & 1.000 & \\
\hline $\mathrm{CT}$ & $38(44.7)$ & $14(43.8)$ & $1.275(0.426-3.819)$ & 0.664 \\
\hline TT & $26(30.6)$ & $12(37.5)$ & $1.614(0.518-5.031)$ & 0.409 \\
\hline Dominant $(\mathrm{CC} v s \mathrm{CT}+\mathrm{TT})$ & & & $1.419(0.514-3.917)$ & 0.500 \\
\hline Recessive (CC+CT vs TT) & & & $1.368(0.583-3.208)$ & 0.472 \\
\hline \multicolumn{5}{|l|}{ TGF- $\beta 1869$} \\
\hline TT & $22(25.9)$ & $6(18.8)$ & 1.000 & \\
\hline $\mathrm{TC}$ & $37(43.5)$ & $15(46.9)$ & $1.488(0.503-4.406)$ & 0.473 \\
\hline $\mathrm{CC}$ & $26(30.6)$ & $11(34.4)$ & $1.550(0.493-4.875)$ & 0.453 \\
\hline Dominant (TT vs $\mathrm{TC}+\mathrm{CC})$ & & & $1.509(0.548-4.152)$ & 0.426 \\
\hline Recessive (TT+TC vs CC) & & & $1.189(0.502-2.820)$ & 0.694 \\
\hline
\end{tabular}

OPLL $=$ ossification of posterior longitudinal ligament; AOR $=$ adjusted odds ratio; $95 \% \mathrm{CI}=95 \%$ confidence interval; $\mathrm{NA}=$ not available; TGF- $\beta 1=$ transforming growth factor- $\beta 1$. P values were adjusted for age.

\section{DISCUSSION}

Abnormalities of bone metabolism play a role in the pathogenesis of OPLL (Furukawa, 2006). OPLL appears to be a polygenic disease caused by environmental and/or genetic factors, including multiple susceptibility genes. Many genetic variants of modest effect are likely to contribute to the occurrence of OPLL by interacting with environmental factors such as mechanical stress (Furukawa, 2006). The TGF- $\beta 1$ gene is considered the leading candidate for increasing individual susceptibility to OPLL because it is an important regulator of bone metabolism (Bonewald and Dallas, 1994; Kamiya et al., 2001; Kawaguchi et al., 2003; Janssens et al., 2005). Bone matrix contains large amounts of latent TGF- $\beta 1$, and active TGF- $\beta 1$ released from bone matrix during bone remodeling may have an important effect for increasing bone resorption as well as bone formation (Bonewald and Mundy, 1990).

Among the polymorphisms found in the TGF- $\beta 1$ gene, the $869 \mathrm{~T}>\mathrm{C}$ polymorphism in exon 1 is the only one studied thus far with regard to OPLL pathogenesis. The three studies that have investigated potential associations between SNP 869T $>C$ and OPLL in Japanese populations have generated contradictory results (Kamiya et al., 2001; Kawaguchi et al., 2003; Horikoshi et al., 2006). For example, Kamiya et al. (2001) have reported that SNP 869T $>$ C is a genetic determinant of predisposition for cervical OPLL, with the $\mathrm{C}$ allele of 869T $>\mathrm{C}$ representing a risk factor for genetic susceptibility to OPLL in a study that included 46 OPLL patients. Conversely, Kawaguchi et al. (2003) found no association between SNP 869T $>C$ and the prevalence of OPLL in a larger patient sample $(\mathrm{N}=369)$, but a stratified analysis based on the area of the ossified lesion identified a significant difference in genotypic distribution 
between patients with isolated cervical OPLL and those with OPLL along the entire spine. That is, patients with the $\mathrm{C}$ allele of $869 \mathrm{~T}>\mathrm{C}$ more frequently displayed OPLL in the cervical, thoracic, or lumbar spine, but the number of stratified subjects was relatively low (cervical, thoracic, or lumbar OPLL, $\mathrm{N}=43$; cervical OPLL alone, $\mathrm{N}=51$ ).

More recently, Horikoshi et al. (2006) have reported a large-scale case-control study ( 711 OPLL patients and 896 controls) that showed no definitive association between the $869 \mathrm{~T}>\mathrm{C}$ polymorphism and genetic susceptibility to OPLL. Our results are similar to those of these large-sample studies showing no association of 869T $>$ C polymorphism with OPLL. Our study showed no significant difference in genotype frequencies of $-509 \mathrm{C}>\mathrm{T}$ and $869 \mathrm{~T}>\mathrm{C}$ polymorphisms between OPLL patients and controls. In addition, combined analysis of $-509 \mathrm{C}>\mathrm{T}$ and $869 \mathrm{~T}>\mathrm{C}$ polymorphisms demonstrated that none was associated with susceptibility to OPLL.

Although defining the exact reasons for the discrepancies between these studies is difficult, possible contributors to the inconsistent outcomes may be differences in study design, sample size, environmental factors such as mechanical stress, levels of gene-environment interactions, and genetic heterogeneity between populations. As examples, the frequencies of the $-509 \mathrm{~T}$ and $869 \mathrm{C}$ alleles among controls in our study were 0.523 and 0.524 , respectively values similar to those observed in healthy Japanese subjects (Kamiya et al., 2001; Kawaguchi et al., 2003) but higher than those in white subjects (McGuigan et al., 2007; Langdahl et al., $2003,2008)$. We showed that the genotype distributions of SNP-509C $>$ T and SNP 869T $>C$ in controls are indeed in Hardy-Weinberg equilibrium, suggesting that the genetic structure of our sample is comparable to that of other studies of TGF- $\beta 1$ polymorphism in OPLL patients.

The $-509 \mathrm{C}>\mathrm{T}$ polymorphism in the promoter region of the TGF- $\beta 1$ gene may alter TGF- $\beta 1$ expression levels, although the molecular mechanism involved is unclear. The $-509 \mathrm{C}>\mathrm{T}$ polymorphism is located in a negative regulatory region of the TGF- $\beta 1$ promoter (Kim et al., 1989). Thus, -509 C may selectively downregulate TGF- $\beta 1$ expression, and increased TGF- $\beta 1$ levels may be associated with $-509 \mathrm{~T}$ owing to the loss of negative regulation (Shah et al., 2006). The $\mathrm{T}$ allele of the $-509 \mathrm{C}>\mathrm{T}$ polymorphism has been associated with an increased risk of diseases such as endometriosis, asthma, and breast cancer (Zhang et al., 2010; Huang et al., 2011; Lee et al., 2011). Furthermore, the associations of the $-509 \mathrm{C}>\mathrm{T}$ polymorphism with bone mass or osteoporosis have been investigated, both alone and in combination with $869 \mathrm{~T}>\mathrm{C}$ polymorphism, but have yielded inconsistent or contradictory results (Yamada et al., 2001; Langdahl et al., 2003, 2008). The $\mathrm{T}$ allele of the $-509 \mathrm{C}>\mathrm{T}$ polymorphism is associated with reduced bone mass in postmenopausal Japanese women (Yamada et al., 2001) and in white men (Langdahl et al., 2008), whereas the $\mathrm{T}$ allele is associated with increased BMD in Danish men and women (Langdahl et al., 2003). Another study has shown no association between the $-509 \mathrm{C}>\mathrm{T}$ polymorphism and BMD or bone loss in a British population (McGuigan et al., 2007).

Despite conflicting results in the association between the $-509 \mathrm{C}>\mathrm{T}$ polymorphism and bone mass, we hypothesized that $-509 \mathrm{C}>\mathrm{T}$ and $869 \mathrm{~T}>\mathrm{C}$ polymorphisms might trigger the development of OPLL by changing the levels of TGF- $\beta 1$ production that affect bone formation. To test this hypothesis, we primarily examined possible associations between selected SNPs $(-509 \mathrm{C}>\mathrm{T}$ in the promoter and $869 \mathrm{~T}>\mathrm{C}$ in the exon 1) and the occurrence of OPLL in a Korean population via genotype analysis. We found no significant difference between OPLL patients and controls in terms of genotype distribution of SNP $-509 \mathrm{C}>\mathrm{T}$ and $869 \mathrm{~T}>\mathrm{C}$. To our knowledge, this study is the first to assess whether the $-509 \mathrm{C}>\mathrm{T}$ polymorphism is associated with genetic susceptibility to OPLL, although the quality of our study is limited by the absence of assays measuring TGF- $\beta 1$ levels in study participants. 
Patients with the mixed or continuous types of OPLL reportedly have the greatest risk of further progression of the ossification area compared with that associated with the segmental and localized subtypes (Kawaguchi et al., 2001; Hori et al., 2006; Kudo et al., 2011). Because our sample sizes for each OPLL subtype (continuous subtype, $\mathrm{N}=30$; mixed subtype, $\mathrm{N}=34$; segmental subtype, $\mathrm{N}=17$; and localized subtype, $\mathrm{N}=17$ ) were relatively small, we stratified OPLL patients into just two groups: an OPLL continuous group (continuous type plus mixed type) and an OPLL segmental group (segmental type plus localized type). Our stratified analysis based on OPLL grouping showed no significant association between TGF- $\beta 1$ polymorphism and susceptibility to cervical OPLL.

We emphasize that our study was a single-hospital-based study, and individuals were recruited from a center that traditionally treats more severe cases of OPLL. We focused on selected candidate genes only using a relatively small sample size of the Korean population without performing genome-wide association studies. These limitations may result in a misunderstanding of the true impact contributed by individual risk factors, additional genetic factors, or ethnic differences.

Our data suggest that under both recessive and dominant genetic models, $-509 \mathrm{C}>\mathrm{T}$ and $869 \mathrm{~T}>\mathrm{C}$ polymorphisms did not correlate significantly with risk levels for OPLL in the Korean population examined. A subgroup analysis based on OPLL subtypes and gender and combination analysis of $-509 \mathrm{C}>\mathrm{T}$ and $869 \mathrm{~T}>\mathrm{C}$ polymorphisms also showed no significant association of between TGF- $\beta 1$ polymorphism and genetic susceptibility for OPLL. Large-scale population studies are required before a definitive conclusion can be drawn regarding significant correlation between specific SNPs in the promoter and exon regions of the TGF- $\beta 1$ gene and genetic susceptibility to OPLL.

\section{ACKNOWLEDGMENTS}

Research supported by the National Research Foundation of Korea Grant funded by the Korean Government (\#2009-0070341) and by a grant of the Korea Healthcare Technology Research and Development Project, Ministry for Health and Welfare Affairs (\#A111016). Current research of Y.D. Teng, A.E. Ropper, and I.B. Han is supported by grants provided by US Department of Veterans Affairs, Center for the Integration of Medicine and Innovative Technology-Department of Defense, State of Massachusetts, and Department of Neurosurgery of Brigham and Women's Hospital/Harvard Medical School.

\section{REFERENCES}

Aufdemorte TB, Fox WC, Holt GR, McGuff HS, et al. (1992). An intraosseous device for studies of bone-healing. The effect of transforming growth-factor beta. J. Bone Joint Surg. Am. 74: 1153-1161.

Bonewald LF and Mundy GR (1990). Role of transforming growth factor-beta in bone remodeling. Clin. Orthop. Relat. Res. 261-276.

Bonewald LF and Dallas SL (1994). Role of active and latent transforming growth factor beta in bone formation. J. Cell Biochem. 55: 350-357.

Furukawa K (2006). Current topics in pharmacological research on bone metabolism: molecular basis of ectopic bone formation induced by mechanical stress. J. Pharmacol. Sci. 100: 201-204.

Geiser AG, Zeng QQ, Sato M, Helvering LM, et al. (1998). Decreased bone mass and bone elasticity in mice lacking the transforming growth factor-beta1 gene. Bone 23: 87-93.

Hori T, Kawaguchi Y and Kimura T (2006). How does the ossification area of the posterior longitudinal ligament progress after cervical laminoplasty? Spine 31: 2807-2812.

Horikoshi T, Maeda K, Kawaguchi Y, Chiba K, et al. (2006). A large-scale genetic association study of ossification of the 
posterior longitudinal ligament of the spine. Hum. Genet. 119: 611-616.

Huang Y, Hao Y, Li B, Xie J, et al. (2011). Lack of significant association between TGF- $\beta 1-590 \mathrm{C} / \mathrm{T}$ polymorphism and breast cancer risk: a meta-analysis. Med. Oncol. 28: 424-428.

Inamasu J, Guiot BH and Sachs DC (2006). Ossification of the posterior longitudinal ligament: an update on its biology, epidemiology, and natural history. Neurosurgery 58: 1027-1039.

Janssens K, ten Dijke P, Janssens S and Van Hul W (2005). Transforming growth factor- $\beta 1$ to the bone. Endocr. Rev. 26: 743-774.

Kamiya M, Harada A, Mizuno M, Iwata H, et al. (2001). Association between a polymorphism of the transforming growth factor-beta1 gene and genetic susceptibility to ossification of the posterior longitudinal ligament in Japanese patients. Spine 26: 1264-1266.

Kawaguchi Y, Kanamori M, Ishihara H, Nakamura H, et al. (2001). Progression of ossification of the posterior longitudinal ligament following en bloc cervical laminoplasty. J. Bone Joint Surg. Am. 83-A: 1798-1802.

Kawaguchi Y, Furushima K, Sugimori K, Inoue I, et al. (2003). Association between polymorphism of the transforming growth factor-beta1 gene with the radiologic characteristic and ossification of the posterior longitudinal ligament. Spine 28: 1424-1426.

Kim SJ, Glick A, Sporn MB and Roberts AB (1989). Characterization of the promoter region of the human transforming growth factor-beta 1 gene. J. Biol. Chem. 264: 402-408.

Kobashi G, Ohta K, Washio M, Okamoto K, et al. (2008). FokI variant of vitamin D receptor gene and factors related to atherosclerosis associated with ossification of the posterior longitudinal ligament of the spine: a multi-hospital casecontrol study. Spine 33: E553-E558.

Kudo H, Furukawa K, Yokoyama T, Ono A, et al. (2011). Genetic differences in the osteogenic differentiation potency according to the classification of ossification of the posterior longitudinal ligament of the cervical spine. Spine 36: 951-957.

Langdahl BL, Carstens M, Stenkjaer L and Eriksen EF (2003). Polymorphisms in the transforming growth factor beta 1 gene and osteoporosis. Bone 32: 297-310.

Langdahl BL, Uitterlinden AG, Ralston SH, Trikalinos TA, et al. (2008). Large-scale analysis of association between polymorphisms in the transforming growth factor beta 1 gene (TGF $\beta 1)$ and osteoporosis: the GENOMOS study. Bone 42: 969-981.

Lee HJ, Kim H, Ku SY, Kim SH, et al. (2011). Transforming growth factor- $\beta 1$ gene polymorphisms in Korean women with endometriosis. Am. J. Reprod. Immunol. 66: 428-434.

Liu Y, Zhao Y, Chen Y, Shi G, et al. (2010). RUNX2 polymorphisms associated with OPLL and OLF in the Han population. Clin. Orthop. Relat. Res. 468: 3333-3341.

Matsui H, Yudoh K and Tsuji H (1996). Significance of serum levels of type I procollagen peptide and intact osteocalcin and bone mineral density in patients with ossification of the posterior longitudinal ligaments. Calcif. Tissue Int. 59: 397-400.

McGuigan FE, Macdonald HM, Bassiti A, Farmer R, et al. (2007). Large-scale population-based study shows no association between common polymorphisms of the TGFB1 gene and BMD in women. J. Bone Miner. Res. 22: 195-202.

Patil AS, Sable RB and Kothari RM (2011). An update on transforming growth factor- $\beta$ (TGF- $\beta$ ): sources, types, functions and clinical applicability for cartilage/bone healing. J. Cell Physiol. 226: 3094-3103.

Saetia K, Cho D, Lee S, Kim DH, et al. (2011). Ossification of the posterior longitudinal ligament: a review. Neurosurg. Focus 30: E1.

Schmidmaier G, Wildemann B, Heeger J, Gabelein T, et al. (2002). Improvement of fracture healing by systemic administration of growth hormone and local application of insulin-like growth factor-1 and transforming growth factor-beta1. Bone 31: 165-172.

Shah R, Hurley CK and Posch PE (2006). A molecular mechanism for the differential regulation of TGF-betal expression due to the common SNP -509C-T (c. -1347C > T). Hum. Genet. 120: 461-469.

Tsukahara S, Miyazawa N, Akagawa H, Forejtova S, et al. (2005). COL6A1, the candidate gene for ossification of the posterior longitudinal ligament, is associated with diffuse idiopathic skeletal hyperostosis in Japanese. Spine 30: 2321-2324.

Wang H, Liu D, Yang Z, Tian B, et al. (2008). Association of bone morphogenetic protein-2 gene polymorphisms with susceptibility to ossification of the posterior longitudinal ligament of the spine and its severity in Chinese patients. Eur. Spine J. 17: 956-964.

Yamada Y, Miyauchi A, Takagi Y, Tanaka M, et al. (2001). Association of the C-509 $\rightarrow$ T polymorphism, alone of in combination with the $\mathrm{T} 869 \rightarrow \mathrm{C}$ polymorphism, of the transforming growth factor-betal gene with bone mineral density and genetic susceptibility to osteoporosis in Japanese women. J. Mol. Med. 79: 149-156.

Zhang Y, Zhang J, Huang J, Li X, et al. (2010). Polymorphisms in the transforming growth factor-betal gene and the risk of asthma: A meta-analysis. Respirology 15: 643-650. 